Check for updates

Cite this: RSC Adv., 2017, 7, 54806

\title{
Natural sliced wood veneer as a universal porous lightweight substrate for supercapacitor electrode materials $\uparrow$
}

\author{
Shaoyi Lyu, (DD *a Yanping Chen, ${ }^{\text {ac }}$ Shenjie Han, ${ }^{a}$ Limin Guo, $^{a} \mathrm{Na}$ Yang $^{a}$ \\ and Siqun Wang $(\mathbb{D}$ *ab
}

\begin{abstract}
We herein report the use of natural sliced wood veneer as a porous lightweight substrate for supercapacitor composite electrodes, where polyaniline/reduced graphene oxide (PANI/RGO) and polypyrrole/reduced graphene oxide (PPy/RGO) were employed as the complex electroactive materials, and were prepared using physical deposition and in situ polymerisation methods. Owing to the hierarchical cellular structure, penetrating channels, and hydrophilic character of the natural wood substrate, both wood electrodes displayed unique morphologies and exhibited high specific capacitances, good capacitance retention, and good cycling stabilities. More specifically, the as-designed PANI/RGO wood and PPy/RGO wood electrodes gave high gravimetric specific capacitances of 931.92 and $848.01 \mathrm{~F} \mathrm{~g}^{-1}$, respectively, at a current density of $2.5 \mathrm{~mA} \mathrm{~cm} \mathrm{~cm}^{-2}$ in a three-electrode test. In addition, the assembled symmetric supercapacitors showed good areal specific capacitances of 0.89 and $0.78 \mathrm{~F} \mathrm{~cm}^{-2}$, respectively, at a sweep rate of $1 \mathrm{mV} \mathrm{s}^{-1}$ in addition to high areal specific energies of 107.70 and $86.96 \mathrm{~mW} \mathrm{~h} \mathrm{~cm}^{-2}$, respectively, at an areal specific power of $0.25 \mathrm{~mW} \mathrm{~cm}^{-2}$. Our results indicate that the use of natural wood as a substrate for supercapacitor electrodes will be an important contribution to the development of green and renewable energy storage devices.
\end{abstract}

Received 16th September 2017 Accepted 21st November 2017

DOI: $10.1039 / c 7 r a 10306 a$

rsc.li/rsc-advances

\section{Introduction}

The application of cellulose-based energy storage materials for lithium-ion batteries and supercapacitors has received unprecedented attention in recent years. ${ }^{1-5}$ In particular, the use of nanocellulose as a carrier or a shaped material in combination with an electrochemically active material (e.g., a conductive polymer or carbon nanomaterial) to form energy storage materials, ${ }^{6-9}$ and the direct carbonisation of nanocellulose into activated carbon materials ${ }^{10-14}$ have been examined in detail. This increased attention regarding nanocellulose is closely related to its excellent properties, which are derived from its biomass source, i.e., wood. However, the production of nanocellulose from wood and wood pulp requires high amounts of energy consumption and produces significant quantities of pollution during the crushing, separation, and purification

${ }^{a}$ Research Institute of Wood Industry, Chinese Academy of Forestry, Beijing 100091, China. E-mail: lvsy@caf.ac.cn; swang@utk.edu; Fax: +86 10 62881937; Tel: +86 10 62889241

${ }^{b}$ Center for Renewable Carbon, University of Tennessee, Knoxville, Tennessee, 37996, USA

'Beijing Engineering Research Center of Cellulose and Its Derivatives, School of Materials Science and Engineering, Beijing Institute of Technology, Beijing 100081, China

$\dagger$ Electronic supplementary information (ESI) available. See DOI: $10.1039 / \mathrm{c} 7 \mathrm{ra} 10306 \mathrm{a}$ procedures. In addition, such processes result in loss of the inherent porous characteristics of natural wood, thereby preventing full exploitation of the beneficial hierarchical structure of this material. The preparation of targeted functional materials exhibiting the inherent porous properties of natural wood is therefore of particular interest.

As one of the most abundant renewable natural resources, wood is of key importance in the area of green chemistry. Wood is essentially a carbohydrate that contains active hydroxyl groups and an elaborate hierarchical porous structure..$^{15,16}$ These features are particularly relevant in the context of functionalised space, and so are beneficial in the preparation of a variety of advanced wood-based functional materials that exhibit special and complex properties. ${ }^{17}$ More specifically, wood contains a range of structural cells, including tracheids (softwood), ducts (hardwood), pits, and perforations, among others. ${ }^{15,16}$ In addition, tubular cells of various geometries and sizes that exhibit different biological functions are grouped together to form a unique porous biomass composite material. Therefore, if we can preserve the structural characteristics of wood and use it directly as a hierarchically well-organised skeleton, we expect that it will be suitable for use in a range of potential applications. For example, the porous structure and surface hydroxyl groups of wood allow the construction of structure-controllable micro/nano functional materials on the wood cell walls by both physical and chemical methods. One 
typical method involves the complete retention of the wood cell wall, followed by the deposition of inorganic nanomaterials, or the in situ polymerisation of an organic polymer to form an organic/inorganic hybrid functional wood material. ${ }^{17-21}$ Thus, through the application of such methods, the micro/nano characteristics of wood can be replicated and retained to the greatest extent possible.

Based on the above concepts, we previously reported the use of sliced wood veneers as porous skeletons for the preparation of two types of electrode materials, namely polypyrrole (PPy)/ wood and reduced graphene oxide (RGO)/wood, by chemical in situ polymerisation and physical deposition methods, respectively, followed by their application in all-solid-state supercapacitor devices. ${ }^{22,23}$ Indeed, due to the inherent porosity and hydrophilic properties of wood, both types of electrode materials exhibited good electrochemical properties. Thus, building on this previous research, we herein report the assembly of the complex electroactive materials PPy/RGO and polyaniline (PANI)/RGO inside the porous cell cavity of wood by a simple two-step strategy to form a network-like electrode material. We expect that our study into the development of a wood-based electrode material and its assembled solid-state supercapacitor devices will lead to further advances in the application of unique wood-based energy storage materials in green and renewable energy storage devices.

\section{Experimental}

\section{Materials}

Natural sliced wood veneers were prepared by rotary microtomy without any chemical treatment. The sliced wood veneers were cut into rectangles measuring $1.0 \times 2.0 \mathrm{~cm}^{2}$ and with a thickness of approximately $200 \mu \mathrm{m}$. Graphene oxide (GO) suspensions $\left(2 \mathrm{mg} \mathrm{mL}{ }^{-1}\right.$, flake diameter $<500 \mathrm{~nm}$ ) were purchased from Nanjing XFNANO Materials Tech Co., Ltd. In addition, the pyrrole and aniline monomers were purchased from the Shanghai Aladdin Reagent Co., Ltd and analytical grade hydrazine hydrate, hydrochloric acid, ferric chloride, and ammonium persulfate were purchased from the Beijing Chemical Reagents Co., Ltd.

\section{Preparation of the wood electrode}

The sliced wood veneers were immersed in a $2 \mathrm{mg} \mathrm{mL} \mathrm{m}^{-1}$ suspension of GO for $5 \mathrm{~min}$ prior to storing in a freezer at $-30{ }^{\circ} \mathrm{C}$ for $2 \mathrm{~h}$, and subsequent freeze-drying using a lyophiliser. The resulting GO-coated wood veneers were then reduced by hydrazine hydrate at $90{ }^{\circ} \mathrm{C}$ over $3 \mathrm{~h}$ to give the reduced GO-coated (RGO-coated) wood veneers. These RGO-coated wood veneers were immersed in either pyrrole or aniline for $3 \mathrm{~min}$, then transferred into a $0.1 \mathrm{~g} \mathrm{~mL}^{-1}$ ferric chloride solution (for the pyrrole system) or a $0.1 \mathrm{~g} \mathrm{~mL}^{-1}$ ammonium persulfate solution (for the aniline solution) to promote the polymerisation reaction, which was allowed to proceed at $4{ }^{\circ} \mathrm{C}$ over $3 \mathrm{~h}$. The ferric chloride and ammonium persulfate solutions employed in the previous step were prepared by the addition of either ferric chloride or ammonium persulfate $(10 \mathrm{~g})$ to a $0.3 \mathrm{M}$ aqueous hydrochloric acid solution $(100 \mathrm{~mL})$. Finally, the resulting PPy/RGO and PANI/RGO wood veneer electrodes were washed with a $0.3 \mathrm{M}$ hydrochloric acid solution and with deionised water to remove any residues, and then vacuum dried at $60{ }^{\circ} \mathrm{C}$ over $1 \mathrm{~h}$.

\section{Preparation of the all-solid-state supercapacitors}

One side of the prepared wood electrode was bonded to the aluminum sheet with a conductive silver paste. The wood electrode was then immersed in the polyvinyl alcohol (PVA)/ $\mathrm{H}_{3} \mathrm{PO}_{4}$ gel electrolyte for approximately $1 \mathrm{~h}$, after which time it was allowed to dry at $25{ }^{\circ} \mathrm{C}$. Two wood electrodes were then pressed gently together to give the sandwich structure of the allsolid-state supercapacitor device (see Fig. S5a $\dagger$ ).

\section{Characterisation and electrical measurements}

Fourier transform infrared spectroscopy (FTIR) was carried out using a Nicolet iS10 spectrometer (Thermo Fisher Scientific Inc., USA), while Raman measurements were carried out using a LabRAM HR Evolution Raman system with $532 \mathrm{~nm}$ diode laser excitation at room temperature (HORIBA Scientific, France). X-ray photoelectron spectroscopy (XPS) was conducted on a PHI 5300 Photoelectron Spectrometer (Perkin 15 Elmer Instruments Co. Ltd., USA), and scanning electron microscopy (SEM) was performed using a Hitachi S-4800 field-emission-gun SEM (Japan) at $5.0 \mathrm{kV}$. Dynamic mechanical analysis (DMA) tests were measured by Anton Paar Physica MCR 301, and conductivity was performed by a ST 2253 4-point probes resistivity measurement system (Suzhou Jingge Electronic Co., Ltd). Electrochemical measurements were carried out on a CHI 660E electrochemical workstation (Shanghai Chenhua Instrument Co., LTD, China) at room temperature. The average areal loadings of the RGO wood, PANI/RGO wood, and PPy/RGO wood electrodes for the three-electrode tests were 1.01, 2.38, and $2.22 \mathrm{mg} \mathrm{cm}^{-2}$, and $0.91,2.26$, and $2.10 \mathrm{mg} \mathrm{cm}^{-2}$ for the twoelectrode tests, respectively. In the three-electrode system, cyclic voltammetry $(\mathrm{CV})$ and galvanostatic charge-discharge (GCD) measurements were conducted between 0 and $0.8 \mathrm{~V}$ in a $1 \mathrm{M} \mathrm{H}_{2} \mathrm{SO}_{4}$ electrolyte solution, in which a Pt electrode and a saturated calomel electrode (SCE) were used as the counter and reference electrodes, respectively. The electrochemical measurements of the supercapacitor devices were carried out using a two-electrode system, where the potential window ranged from 0 to $0.8 \mathrm{~V}$. Electrochemical impedance spectroscopy (EIS) was performed with a frequency range of 0.001 to $10^{5} \mathrm{~Hz}$. For the three-electrode tests, the areal specific capacitance $C_{\mathrm{s}}\left(\mathrm{F} \mathrm{cm}^{-2}\right)$ and the gravimetric specific capacitance $C_{\mathrm{g}}$ $\left(\mathrm{F}^{-1}\right)$ were calculated as follows: $C_{\mathrm{s}}=\left(\int I \mathrm{~d} U\right) /(\nu S U)$ and $C_{\mathrm{g}}=(I \Delta t) /(m U)$, where $I(\mathrm{~A}), \nu\left(\mathrm{V} \mathrm{s}^{-1}\right), S\left(\mathrm{~cm}^{2}\right), U(\mathrm{~V}), \Delta t(\mathrm{~s})$, and $m$ $(\mathrm{g})$, are the current, voltage sweep rate, working area of the electrode, voltage window, discharge time, and total electrode weight, respectively. For the two-electrode tests, $C_{\mathrm{s}^{\prime}}=4\left(\int I \mathrm{~d} U\right) /(\nu S U)$ or $C_{\mathrm{s}^{\prime \prime}}=4(I \Delta t) /(S U)$, and $C_{\mathrm{g}^{\prime}}=$ $4(I \Delta t) /(m U)$, where $C_{\mathrm{s}^{\prime}}, C_{\mathrm{s}^{\prime \prime}}$, and $C_{\mathrm{g}^{\prime}}$ are the areal specific 
capacitance and gravimetric specific capacitance of the supercapacitor devices, respectively. The areal energy $E\left(\mathrm{~mW} \mathrm{~h} \mathrm{~cm}^{-2}\right)$ and the areal power $P\left(\mathrm{~mW} \mathrm{~cm}^{-2}\right)$ of the supercapacitor were obtained according to the expressions $E=1 / 4\left(U^{2} C_{\mathrm{s}^{\prime \prime}} / 2\right)$ and $P=$ $E / \Delta t$, respectively.

\section{Results and discussion}

A schematic depiction of the process employed for preparation of the wood electrodes is provided in Fig. 1a. As shown, after coating the natural sliced wood veneers with a layer of RGO, coating with either PANI or PPy was carried out via an in situ polymerisation technique. Comparison of the morphologies of the original wood sample and the prepared wood electrodes by SEM (see Fig. 2 and S1 $\dagger$ ) indicated that the natural wood sample exhibited a smooth surface (Fig. S1b and $\mathrm{c}^{\dagger}$ ), while deposition of the RGO nanosheet onto the wood veneer produced a wrinkled sheet structure (Fig. 2a and b). In addition, portions of the RGO nanosheet also formed a discontinuous lamellar structure inside the wood cell lumen, which may be caused by the freezedrying process (Fig. S1d inset†). ${ }^{24-26}$ Following the in situ polymerisation stage, the RGO surface was appended with a large number of rod-shaped PANI (Fig. 2c and d) or granular PPy (Fig. 2e and f) particles to form the conductive polymer layers. Indeed, at higher magnifications, it was found that both PANI and PPy exhibited good recombination with RGO (Fig. 2d and f). Furthermore, network structures of RGO and the conductive polymers were formed in a few cases, such as for the PPy/RGO wood sample (Fig. 2e). Thus, we further analysed the elemental distribution on PPy/RGO wood using energy dispersive spectroscopy (EDS), as shown in Fig. S1g-i. $\dagger$ As indicated, $\mathrm{N}$ and $\mathrm{C}$ were well dispersed within the porous cell structure of the wood sample, which indicates that the conductive polymer and the RGO form a complex on the wood surface. In addition, examination of the wood veneer cross section showed a very regular and porous cell structure, which contained a naturally aligned straight channel structure $(20-50 \mu \mathrm{m})$ passing from top
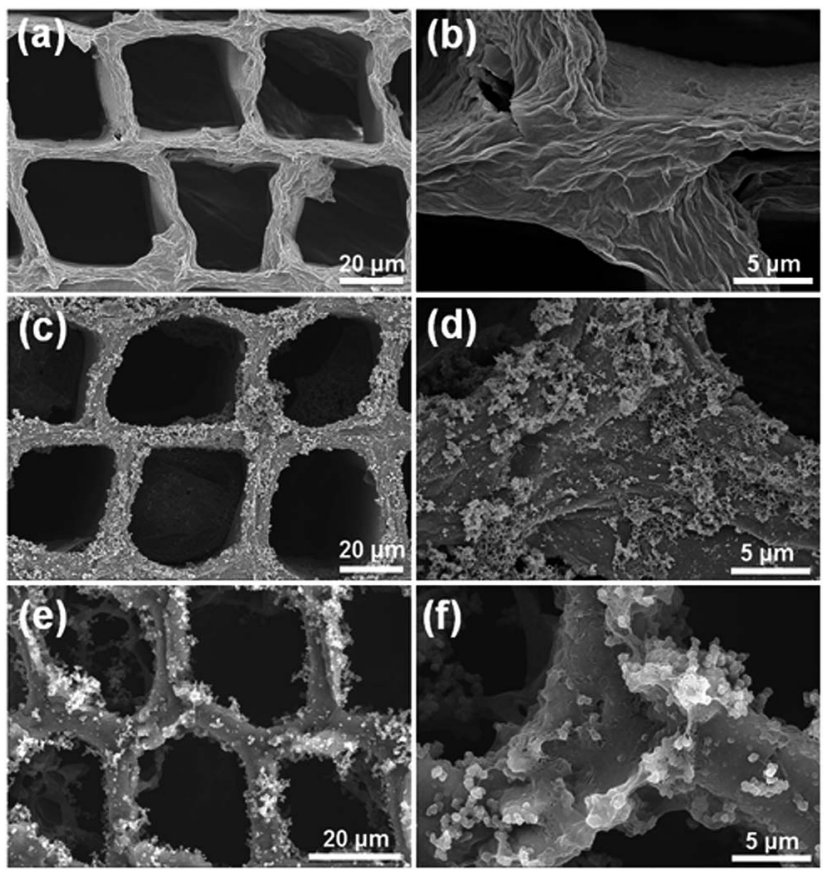

Fig. 2 Surface morphology SEM images of the (a) RGO wood, (c) PANI/RGO wood, and (e) PPy/RGO wood samples. Magnified SEM images of the (b) RGO wood, (d) PANI/RGO wood, and (f) PPy/RGO wood samples.

to bottom (Fig. S1a†). These results indicate that following RGO attachment and PANI or PPy in situ polymerisation, these porous channels remained unblocked (Fig. S1d-f f†). As such, the penetrating channels provide convenient conditions for electron transfer and ion diffusion during electrochemical reactions, as shown in Fig. 1b. Furthermore, the wood matrix appeared to retain its lyophilic properties in the PANI/RGO and PPy/RGO wood electrodes, which can promote efficient ion penetration throughout the entire supercapacitor.
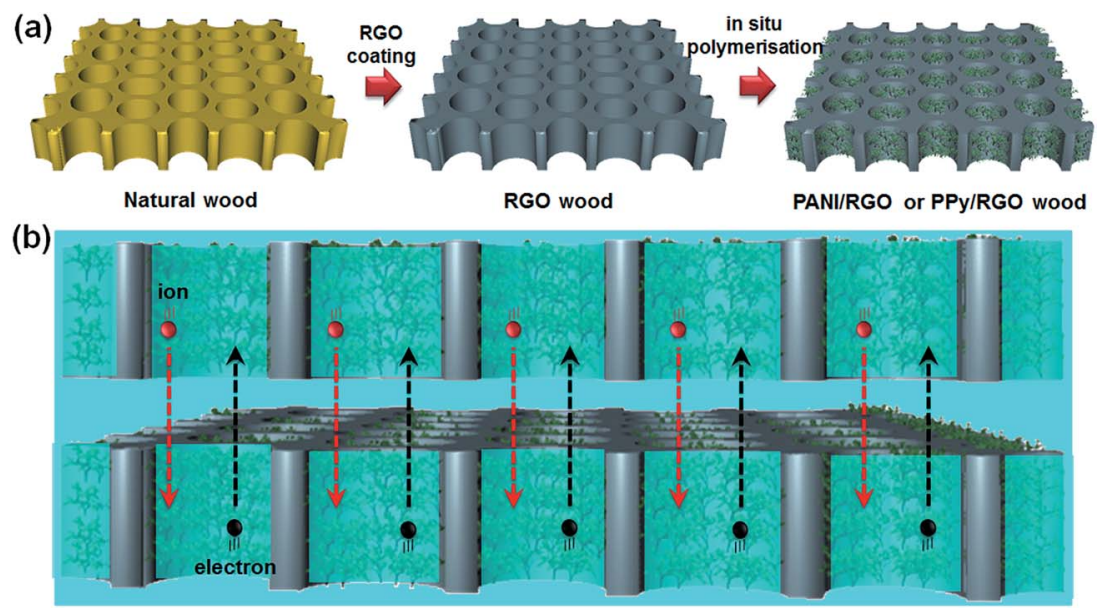

Fig. 1 (a) Schematic representation of the process employed for preparation of the wood electrodes. (b) Schematic representation of ion diffusion and electron transfer in the porous channels of the assembled wood-based supercapacitors. The blue shading represents the gel electrolyte. 
To further examine the composite structures of the RGO wood, PANI/RGO wood, and PPy/RGO wood electrodes, FTIR spectroscopy, Raman spectroscopy, and XPS were employed to analyse the structural variations between the different wood electrodes (see Fig. 3). In the FTIR spectra, the key signals observed for the RGO wood, PANI/RGO wood, and PPy/RGO wood samples at 1630,1633 , and $1631 \mathrm{~cm}^{-1}$ were attributed to $\mathrm{C}-\mathrm{OH}$ stretching, while those observed at 1395,1384 , and $1382 \mathrm{~cm}^{-1}$ originated from $\mathrm{C}-\mathrm{O}$ stretching. ${ }^{27}$ In addition, the intense peak observed at $1117 \mathrm{~cm}^{-1}$ in the FTIR spectrum of PANI/RGO wood was assigned to the $\mathrm{N}=\mathrm{Q}=\mathrm{N}$ stretching vibration, and represented the characteristic peak of PANI. ${ }^{28}$ Similarly, the peaks observed at 1462 and $1166 \mathrm{~cm}^{-1}$ for the $\mathrm{PPy} / \mathrm{RGO}$ wood sample corresponded to the $\mathrm{C}-\mathrm{N}$ stretching vibrations of PPy. ${ }^{22}$

As shown in Fig. 3b, the Raman spectra were also characteristic of the wood electrodes structures. More specifically, RGO wood can be characterised by the D and G peaks of RGO which appeared at 1325 and $1591 \mathrm{~cm}^{-1}$, respectively. The Raman spectra of PANI/RGO wood and PPy/RGO wood also exhibited D $\left(1331 \mathrm{~cm}^{-1}\right)$ and $\mathrm{G}\left(1566\right.$ and $\left.1590 \mathrm{~cm}^{-1}\right)$ peaks similar to those of RGO. ${ }^{29}$ In addition, the PANI/RGO wood sample gave a series of peaks that could be attributed to the PANI structure, including two signals at 1161 and $1213 \mathrm{~cm}^{-1}$ (C- $\mathrm{H}$ bending) and a single peak at $1468 \mathrm{~cm}^{-1}(\mathrm{C}=\mathrm{N}$ bending).$^{30}$ Furthermore, PPy/RGO wood produced weak signals at 1044 and $978 \mathrm{~cm}^{-1}$, which were attributed to the in-plane and out-of-plane vibrations of the $\mathrm{N}-\mathrm{H}$ and $\mathrm{C}-\mathrm{H}$ moieties. ${ }^{31}$

XPS was then employed to characterise the structural properties of the RGO wood, PANI/RGO wood, and PPy/RGO wood samples. The survey spectra of all three samples (see Fig. S2a $\dagger$ ) confirmed the presence of $\mathrm{C}, \mathrm{N}, \mathrm{O}, \mathrm{S}$, and $\mathrm{Cl}$, where $\mathrm{Cl}$ and $\mathrm{S}$ originated from the doping elements of PPy and PANI structures, respectively. As shown in Fig. $3 \mathrm{c}$ and d, the C 1s peaks of PANI/RGO wood and PPy/RGO wood were composed of four different carbon functional groups, namely $\mathrm{C}=\mathrm{C} / \mathrm{C}-\mathrm{C}$


(d)

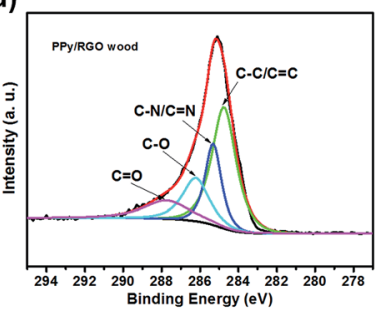

Fig. 3 The (a) FTIR and (b) Raman spectra of PANI/RGO wood, PPy/ RGO wood, and RGO wood samples. High-resolution XPS C 1s spectra of (c) PANI/RGO wood and (d) PPy/RGO wood.
(284.8 eV), $\mathrm{C}-\mathrm{N} / \mathrm{C}=\mathrm{N}(285.6$ and $285.3 \mathrm{eV}), \mathrm{C}-\mathrm{O}(286.6$ and 286.2 $\mathrm{eV})$, and $\mathrm{C}=\mathrm{O}(288.3$ and $287.8 \mathrm{eV}){ }^{31}$ Indeed, the signals corresponding to $\mathrm{C}-\mathrm{N} / \mathrm{C}=\mathrm{N}$ were characteristic peak of the PANI/ RGO and PPy/RGO compound. Furthermore, the $\mathrm{N}$ 1s signal was deconvoluted into three peaks with binding energies of $398.5(=\mathrm{NH}-), 399.6(-\mathrm{NH}-)$, and $401.3 \mathrm{eV}\left(-\mathrm{NH}^{+}-\right)$for the PANI/ RGO wood sample (Fig. S2b $\mathrm{b}^{\dagger}$ ), and $399.6(-\mathrm{NH}-), 400.3\left(-\mathrm{N}^{+}-\right)$, and $401.5 \mathrm{eV}\left(-\mathrm{NH}^{+}-\right)$for the PPy/RGO wood sample (Fig. S2c广广) ${ }^{22,28}$ These results therefore confirm that the active materials PANI, PPy, and RGO were successfully attached onto the wood veneer samples. The PANI/RGO, PPy/RGO and RGO wood electrodes also have good mechanical properties (Fig. S5c $\dagger$ ), the storage moduli $\left(G^{\prime}\right)$ can reach to $1.38 \times 10^{9}$, $2.36 \times 10^{9}$ and $5.11 \times 10^{8} \mathrm{~Pa}$ at a frequency of $0.1 \mathrm{rad} \mathrm{s}^{-1}$, respectively.

The electrochemical properties of the three prepared electrodes were then investigated in an aqueous $1 \mathrm{M} \mathrm{H}_{2} \mathrm{SO}_{4}$ electrolyte using a three-electrode system where the wood electrodes were employed as the working electrodes without the addition of any adhesive. Thus, Fig. 4a shows the CV curves of three wood electrodes at a scan rate of $5 \mathrm{mV} \mathrm{s}^{-1}$. Notably, the current densities of PANI/RGO wood and PPy/RGO wood were significantly larger than that of RGO wood. In addition, the PANI- and PPy-coated samples exhibited strong redox peaks, which coincided with the pseudocapacitor behaviour of PANI and PPy. More specifically, this can be attributed to the leucoemeraldine/emeraldine and emeraldine/pernigraniline transitions of $\mathrm{PANI}^{28}$ and the doping/de-doping process of PPy ${ }^{31}$ Furthermore, the CV curves of PANI/RGO wood and PPy/ RGO wood obtained at scan rates ranging from 5 to $200 \mathrm{mV} \mathrm{s}^{-1}$ further revealed that as the scan rate was increased, the cathodic peaks shifted positively while the anodic peaks shifted
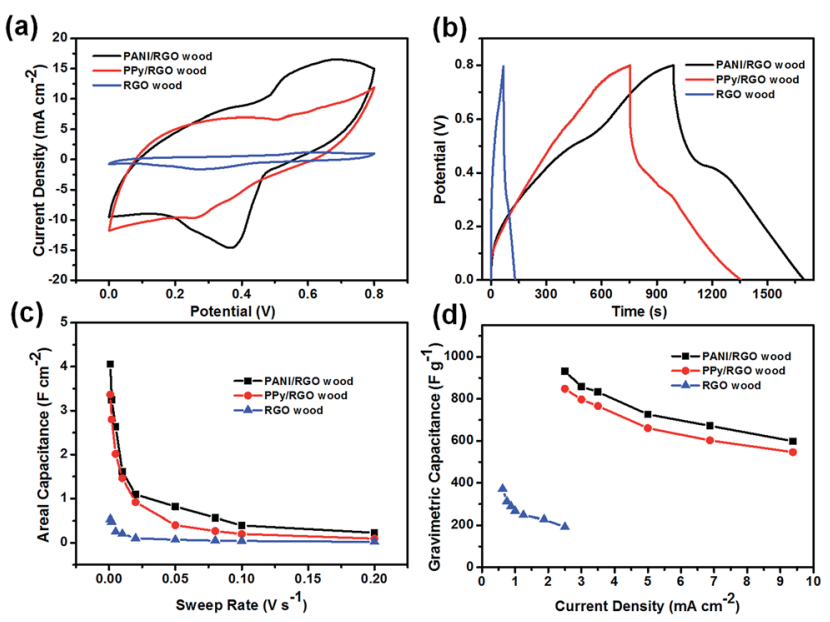

Fig. 4 (a) CV curves of the RGO wood, PANI/RGO wood, and PPy/ RGO wood electrodes obtained at a sweep rate of $5 \mathrm{mV} \mathrm{s}^{-1}$. (b) GCD curves of the three wood electrodes at a current density of $2.5 \mathrm{~mA}$ $\mathrm{cm}^{-2}$. (c) Areal capacitances of the three wood electrodes at different sweep rates. (d) Gravimetric capacitances of the three wood electrodes at different current densities. The electrochemical performances of three wood electrodes were examined using threeelectrode test systems. 
negatively (Fig. S3a and $\mathrm{b} \dagger$ ), likely due to the internal resistance of the electrodes. Moreover, the CV curves obtained for RGO wood exhibited a pair of weak redox signals (Fig. S3c and S5b $\dagger$ ), due to the incomplete reduction of RGO. This resulted in the formation of a surface bearing oxygen-containing functional groups, which undergo redox reactions during the forward and negative potential shifts.

The galvanostatic charge/discharge curves of the three electrodes were then obtained at a current density of $2.5 \mathrm{~mA} \mathrm{~cm}^{-2}$, as shown in Fig. 4 b. More specifically, the charge/discharge curves of the PANI/RGO wood and PPy/RGO wood electrodes exhibited curved charge and discharge lines corresponding to pseudocapacitance, while the relatively symmetrical straight lines observed for the RGO wood electrode demonstrated double-layer capacitance behaviour (Fig. S3d-f $\dagger$ ). In addition, the areal and gravimetric specific capacitances of all samples are presented in Fig. $4 \mathrm{c}$ and d. As indicated, the areal specific capacitances of the PANI/RGO wood and PPy/RGO wood electrodes were significantly higher than that of the RGO wood electrode, reaching values of 4.05 and $3.36 \mathrm{~F} \mathrm{~cm}^{-2}$, respectively, at a low sweep rate of $1 \mathrm{mV} \mathrm{s}^{-1}$, while that of RGO wood gave a significantly lower value of $0.53 \mathrm{~F} \mathrm{~cm}^{-2}$. The gravimetric specific capacitances of the PANI/RGO wood and PPy/RGO wood electrodes were then calculated from the discharge curves to give values of 931.92 and $848.01 \mathrm{~F} \mathrm{~g}^{-1}$, respectively, at a current density of $2.5 \mathrm{~mA} \mathrm{~cm}$, which is again larger than that of RGO wood (i.e., $192.61 \mathrm{~F} \mathrm{~g}^{-1}$ at a current density of $2.5 \mathrm{~mA} \mathrm{~cm}^{-2}$ ). In addition, upon increasing the current density, a slight decrease in the gravimetric specific capacitance was observed, with capacitances of 598.67 (64.24\% of the initial capacitance) and $546.69 \mathrm{~F} \mathrm{~g}^{-1}$ (64.46\% of the initial capacitance) being calculated at a high current density of 9.375 $\mathrm{mA} \mathrm{cm} \mathrm{cm}^{-2}$ for the PANI/RGO wood and PPy/RGO wood electrodes, respectively. The corresponding gravimetric specific capacitance of the RGO wood electrode was reduced to $51.73 \%$ of the initial capacitance when the current density was increased from 0.625 to $2.5 \mathrm{~mA} \mathrm{~cm}^{-2}$. The gravimetric specific capacitances here is higher than that of the graphene/PANI, ${ }^{32}$ PANI/N-doped porous carbon,,$^{33} \mathrm{PANI} /$ activated wood derived carbon ${ }^{34}$ and the cotton-based PPy/RGO ${ }^{35}$ (Table S1 $\dagger$ ).

Furthermore, EIS was employed to determine the interior resistances of the PANI/RGO wood, PPy/RGO wood, and RGO wood electrodes (Fig. S3g $\dagger$ ), with equivalent series resistance (ESR) values of $6.58,5.82$, and $16.03 \Omega$, respectively, being obtained from the Nyquist plots, thereby confirming the relatively small electronic resistance of the electrodes, in addition to a low electrolyte resistance. The electrical conductivity measured by the 4-point probes method also confirms that the wood electrode has a lower resistance. The conductivity of RGO wood, PANI/RGO wood, and PPy/RGO wood electrodes are 0.08, 1.96 and $1.83 \mathrm{~S} \mathrm{~cm}^{-1}$, respectively. These results can likely be attributed to the unique honeycomb porous structure and penetrating channels of the wood electrodes, which facilitates efficient electrolyte infiltration. ${ }^{22,23}$ In addition, the natural hydrophilic properties of wood are also be beneficial to the efficient diffusion of ions of an aqueous electrolyte through the wood electrodes, which guarantees accommodation of the ions on the surfaces of the electroactive material. ${ }^{36}$
The electrochemical behaviours of the PANI/RGO wood and PPy/RGO wood electrode-containing symmetric supercapacitors (SCs) were then evaluated in a two-electrode system using PVA/ $\mathrm{H}_{3} \mathrm{PO}_{4}$ gel as the electrolyte. Thus, CV curves obtained using sweep rates ranging from 5 to $200 \mathrm{mV} \mathrm{s}^{-1}$ are shown in Fig. 5a and $b$, where rough rectangular mirror images without obvious redox peaks were observed. Interestingly, upon increasing the scan rate, only slight deformation of the CV curves was observed, although this was more pronounced above $200 \mathrm{mV} \mathrm{s}^{-1}$. Moreover, the GCD curves of these two SCs are illustrated in Fig. 5c and d. As shown, neither curve exhibited ideal symmetrical triangular shapes, likely due to the significant pseudocapacitance contribution of PANI and PPy. Furthermore, the EIS curves gave ESR values of 12.85 and $8.69 \Omega$ for the PANI/ RGO and PPy/RGO wood SCs, respectively (Fig. S4a and $\mathrm{b}^{\dagger}$ ), thereby demonstrating the good conductivity imparted by the honeycomb porous structures of the electrodes.

As indicated in Fig. 6a, the areal specific capacitances of the PANI/RGO wood and PPy/RGO wood SC electrodes were calculated from the $\mathrm{CV}$ curves to be 0.89 and $0.78 \mathrm{~F} \mathrm{~cm}^{-2}$, respectively, at a low sweep rate of $1 \mathrm{mV} \mathrm{s}^{-1}$. Interestingly, even at a high sweep rate of $10 \mathrm{mV} \mathrm{s}^{-1}$, the capacitances remained relatively high (i.e., 0.39 and $0.35 \mathrm{~F} \mathrm{~cm}^{-2}$, respectively). These results indicate that the retention of specific capacitance is general upon increasing the sweep rate. Furthermore, the areal capacitance values of our systems are significantly higher than those of other recently reported electrodes, such as paper/PPy electrodes, ${ }^{37}$ cellulose/PPy/carbon filament electrodes, ${ }^{38}$ bacterial cellulose (BC)/PPy/carbon nanotube electrodes, ${ }^{39}$ paper-based graphite/ PANI electrodes, ${ }^{40}$ and carbon nanotube/PANI hydrogel film electrodes. ${ }^{\mathbf{4 1}}$ Moreover, the gravimetric capacitances calculated from the discharge curves reached $298.52 \mathrm{~F} \mathrm{~g}^{-1}$ for the PANI/RGO wood SC electrode and $258.82 \mathrm{~F} \mathrm{~g}^{-1}$ for the PPy/RGO wood SC electrode at a current density of $0.50 \mathrm{~mA} \mathrm{~cm}{ }^{-2}$. Even upon increasing the current density to $1.75 \mathrm{~mA} \mathrm{~cm}^{-2}, 54.46$ and
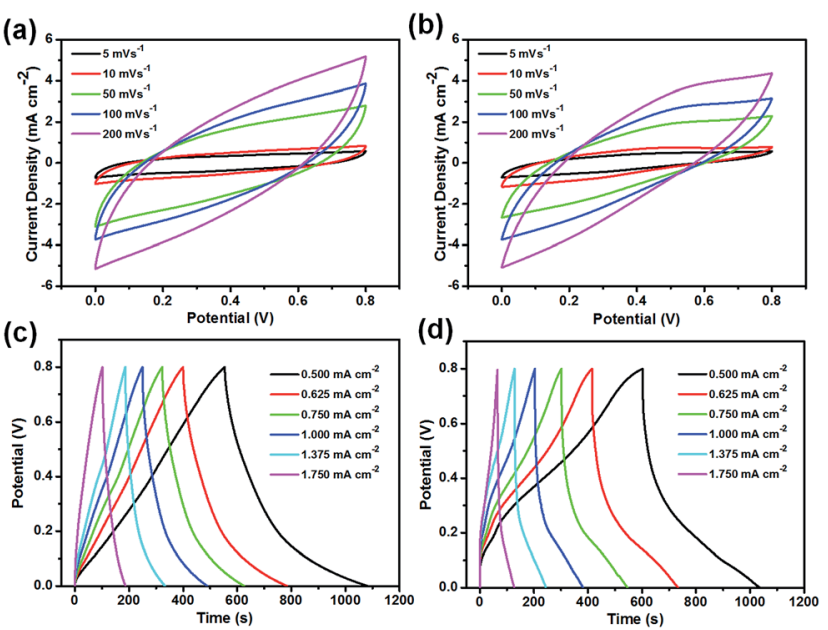

Fig. 5 CV curves of the (a) PANI/RGO wood and (b) PPy/RGO wood electrode-containing supercapacitors at different sweep rates. GCD curves of the (c) PANI/RGO wood and (d) PPy/RGO wood electrodecontaining supercapacitors at different current densities. 
(a)

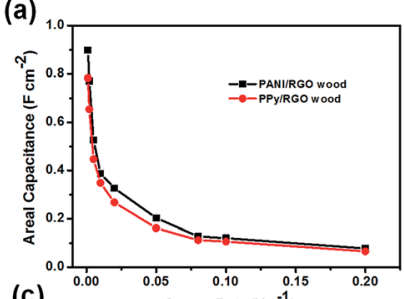

(c)

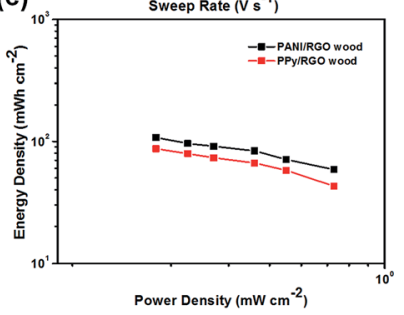

(b)

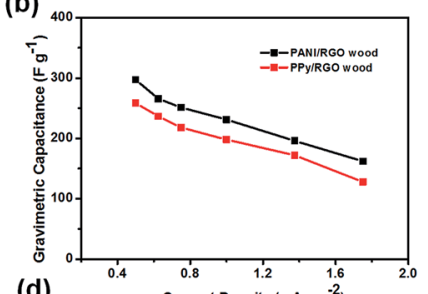

(d)

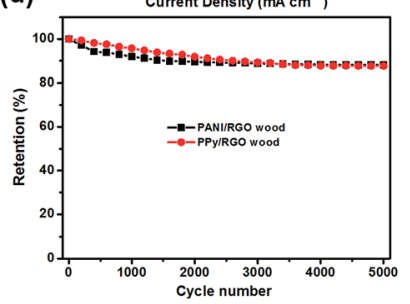

Fig. 6 (a) Areal capacitances of the PANI/RGO wood and PPy/RGO wood electrode-containing supercapacitors at different sweep rates. (b) Gravimetric capacitances of the assembled supercapacitors at different current densities. (c) Ragone plots of the power density versus the energy density for the assembled supercapacitors. (d) Cycling stabilities of the assembled supercapacitors.

$54.46 \%$ capacitances were retained for the PANI/RGO wood and PPy/RGO wood SC electrodes, respectively.

Energy density and power density are also important indicators when evaluating the performance of an SC. Thus, Ragone plots of areal specific power against areal specific energy for the PANI/RGO wood and PPy/RGO wood SCs are shown in Fig. 6c. In both cases, the obtained curves indicate that the areal specific energy decreased slowly upon increasing the areal specific power. More specifically, the maximum areal specific energy of


specific power of $0.25 \mathrm{~mW} \mathrm{~cm} \mathrm{~cm}^{-2}$, while that of the PPy/RGO wood SC reached $86.96 \mathrm{~mW} \mathrm{~h} \mathrm{~cm}{ }^{-2}$ at $0.25 \mathrm{~mW} \mathrm{~cm}^{-2}$. In addition, upon increasing the areal specific power to $0.70 \mathrm{~mW}$ $\mathrm{cm}^{-2}$, acceptable areal specific energies of 58.66 and $42.84 \mathrm{~mW}$ $\mathrm{cm}^{-2}$ were obtained for the PANI/RGO wood and PPy/RGO wood SCs, respectively. Interestingly, these areal specific energies and powers are superior to those of PANI/RGO/BC SCs, ${ }^{42} \mathrm{PPy} / \mathrm{BC} /$ RGO paper $\mathrm{SCs}^{43}$ PPy/RGO membrane $\mathrm{SCs},{ }^{44}$ and photo paper-based PANI/manganese oxide SCs. ${ }^{45}$

Finally, the stabilities of the PANI/RGO wood and PPy/RGO wood SCs were evaluated by CV measurements at $20 \mathrm{mV} \mathrm{s}^{-1}$, as shown in Fig. 6d, S4c and d. $\dagger$ More specifically, the PANI/ RGO wood electrode retained $88.11 \%$ of its initial capacitance after 5000 cycles, while the PPy/RGO wood electrode retained $87.7 \%$ of its initial capacitance, thereby demonstrating the good cycling stability of these wood SCs.

Thus, the above results for the PANI/RGO wood and PPy/RGO wood SCs indicated that the wood electrodes prepared herein exhibited high specific capacitances, low ESRs, good capacitance retention, and good cycling stabilities, which could be mainly attributed to the honeycomb porous structure and penetrating channels of the natural wood source, which permits the storage and transportation of aqueous electrolytes to enhance ion transport and electron diffusion. ${ }^{22,23,32}$

\section{Conclusions}

In summary, we herein demonstrated the use of natural sliced wood veneer as a porous lightweight substrate for supercapacitor composite electrodes where polyaniline/reduced graphene oxide (PANI/RGO) and polypyrrole/reduced graphene oxide (PPy/RGO) were employed as complex electroactive materials. By taking advantage of the unique hierarchical cellular structure, penetrating channels, and hydrophilic character of the natural wood substrate, PANI/RGO wood and PPy/ RGO wood electrodes were prepared that exhibited high gravimetric specific capacitances of 931.92 and $848.01 \mathrm{~F} \mathrm{~g}^{-1}$, respectively, in the three-electrode test. In addition, the assembled symmetric supercapacitors displayed good areal specific capacitances of 0.89 and $0.78 \mathrm{~F} \mathrm{~cm}^{-2}$ in addition to high areal specific energies of 107.70 and $86.96 \mathrm{~mW} \mathrm{~h} \mathrm{~cm}^{-2}$, respectively, at an areal specific power of $0.25 \mathrm{~mW} \mathrm{~cm} \mathrm{~cm}^{-2}$. Furthermore, both electrodes exhibited good cycling stabilities. These results therefore suggest that the use of natural wood as a substrate for supercapacitor electrodes allows preservation of the hierarchical structure and penetrating channels of wood, and so subsequent functionalisation of these structures is expected to lead to significant advances in the development of green and renewable energy storage devices.

\section{Conflicts of interest}

There are no conflicts to declare.

\section{Acknowledgements}

This work was supported by a Special Fund from the National Natural Science Foundation of China (No. 31400504) and Fundamental Research Funds from the Central Non-profit Research Institution of CAF (No. CAFYBB2014QB041).

\section{Notes and references}

1 M. M. Pérez-Madrigal, M. G. Edo and C. Alemán, Green Chem., 2016, 18, 5930-5956.

2 L. Nyholm, G. Nyström, A. Mihranyan and M. Strømme, Adv. Mater., 2011, 23, 3751-3769.

3 L. Liu, Z. Niu, L. Zhang, W. Zhou, X. Chen and S. Xie, Adv. Mater., 2014, 26, 4855-4862.

4 D. Ge, L. Yang, L. Fan, C. Zhang, X. Xiao, Y. Gogotsi and S. Yang, Nano Energy, 2015, 11, 568-578.

5 S. Lyu, H. Chang, F. Fu, L. Hu, J. Huang and S. Wang, J. Power Sources, 2016, 327, 438-446.

6 X. Du, Z. Zhang, W. Liu and Y. Deng, Nano Energy, 2017, 35, 299-320.

7 R. Sabo, A. Yermakov, C. T. Law and R. Elhajjar, J. Renewable Mater., 2016, 4, 297-312.

8 Q. Zheng, Z. Cai, Z. Ma and S. Gong, ACS Appl. Mater. Interfaces, 2015, 7, 3263-3271.

9 F. Hoeng, A. Denneulin and J. Bras, Nanoscale, 2016, 8, 13131-13154. 
10 G. Zu, J. Shen, L. Zou, F. Wang, X. Wang, Y. Zhang and X. Yao, Carbon, 2016, 99, 203-211.

11 N. F. Zhang, Y. M. Zhou, X. Y. Yang, C. L. Tang, H. Wu and N. S. Zhong, RSC Adv., 2014, 4, 17549-17554.

12 F. Lai, Y. E. Miao, L. Zuo, Y. Zhang and T. Liu, ChemNanoMat, 2016, 2, 212-219.

13 Y. Lu, G. Ye, X. She, S. Wang, D. Yang and Y. Yin, ACS Sustainable Chem. Eng., 2017, 5, 8729-8737.

14 G. Ye, X. Zhu, S. Chen, D. Li, Y. Yin, Y. Lu, S. Komarneni and D. Yang, J. Mater. Chem. A, 2017, 5, 8247-8254.

15 J. L. Bowyer, R. Shmulsky and J. G. Haygreen, Forest products and wood science: an introduction, Wiley-Blackwell, New Jersey, 5th edn, 2007.

16 D. N. S. Hon and N. Shiraishi, Wood and cellulosic chemistry, CRC Press, Boca Raton, 2nd edn, 2000.

17 I. Burgert, E. Cabane, C. Zollfrank and L. Berglund, Int. Mater. Rev., 2016, 60, 431-450.

18 V. Merk, M. Chanana, N. Gierlinger, A. M. Hirt and I. Burgert, ACS Appl. Mater. Interfaces, 2014, 6, 9760-9767.

19 V. Merk, M. Chanana, T. Keplinger, S. Gaan and I. Burgert, Green Chem., 2015, 17, 1423-1428.

20 E. Cabane, T. Keplinger, T. Künniger, V. Merk and I. Burgert, Sci. Rep., 2016, 6, 31287.

21 T. Keplinger, E. Cabane, J. K. Berg, J. S. Segmehl, P. Bock and I. Burgert, Adv. Mater. Interfaces, 2016, 3, 1-6.

22 S. Lv, F. Fu, S. Wang, J. Huang and L. Hu, RSC Adv., 2014, 5, 2813-2818.

23 S. Lv, F. Fu, S. Wang, J. Huang and L. Hu, Electron. Mater. Lett., 2015, 11, 633-642.

24 S. Deville, Adv. Eng. Mater., 2008, 10, 155-169.

25 W. L. Li, K. Lu and J. Y. Walz, Int. Mater. Rev., 2013, 57, 3760.

26 L. Qiu, J. Z. Liu, S. L. Y. Chang, Y. Wu and D. Li, Nat. Commun., 2012, 3, 1241.

27 M. Shateri-Khalilabad and M. E. Yazdanshenas, Cellulose, 2013, 20, 963-972.
28 L. Zhang, D. Huang, N. Hu, C. Yang, M. Li, H. Wei, Z. Yang, Y. Su and Y. Zhang, J. Power Sources, 2017, 342, 1-8.

29 N. Hu, Y. Wang, J. Chai, R. Gao, Z. Yang, S. W. Kong and Y. Zhang, Sens. Actuators, B, 2012, 163, 107-114.

30 N. Hu, L. Zhang, C. Yang, J. Zhao, Z. Yang, H. Wei, H. Liao, Z. Feng, A. Fisher and Y. Zhang, Sci. Rep., 2016, 6, 19777.

31 S. Li, C. Zhao, K. Shu, C. Wang, Z. P. Guo, G. G. Wallace and H. K. Liu, Carbon, 2014, 79, 554-562.

32 K. Li, J. Liu, Y. Huang, F. Bu and Y. Xu, J. Mater. Chem. A, 2017, 5, 5466-5474.

33 S. N. Guo, H. K. Shen, Z. F. Tie, S. Zhu, P. H. Shi, J. C. Fan, Q. J. Xu and Y. L. Min, J. Power Sources, 2017, 359, 285-294.

34 D. Liu, S. Yu, Y. Shen, H. Chen, Z. Shen, S. Zhao, S. Fu, Y. Yu and B. Bao, Ind. Eng. Chem. Res., 2015, 54, 12570-12579.

35 J. Xu, D. Wang, Y. Yuan, W. Wei, L. Duan, L. Wang, H. Bao and W. Xu, Org. Electron., 2015, 24, 153-159.

36 C. Chen, Y. Zhang, Y. Li, J. Dai, J. Song, Y. Yao, Y. Gong, I. Kierzewski, J. Xie and L. Hu, Energy Environ. Sci., 2017, 10, 538-545.

37 L. Yuan, B. Yao, B. Hu, K. Huo, W. Chen and J. Zhou, Energy Environ. Sci., 2013, 6, 470-476.

38 A. Razaq, L. Nyholm, M. Sjödin, M. Strømme and A. Mihranyan, Adv. Energy Mater., 2012, 2, 494.

39 S. Li, D. Huang, J. Yang, B. Zhang, X. Zhang, G. Yang, M. Wang and Y. Shen, Nano Energy, 2014, 9, 309-317.

40 B. Yao, L. Yuan, X. Xiao, J. Zhang, Y. Qi, J. Zhou, J. Zhou, B. Hu and W. Chen, Nano Energy, 2013, 2, 1071-1078.

41 S. Zeng, H. Chen, F. Cai, Y. Kang, M. Chen and Q. Li, J. Mater. Chem. A, 2015, 3, 23864-23870.

42 R. Liu, L. Ma, S. Huang, J. Mei, J. Xu and G. Yuan, New J. Chem., 2016, 41, 857-864.

43 L. Ma, R. Liu, H. Niu, F. Wang, L. Liu and Y. Huang, Electrochim. Acta, 2016, 222, 429-437.

44 J. Zhang, P. Chen, B. H. Oh and M. B. Chanpark, Nanoscale, 2013, 5, 9860-9866.

45 W. Xu, A. Sumboja, L. F. Wan, Y. Y. Chao, K. Tsukagoshi and P. S. Lee, RSC Adv., 2013, 3, 15827-15833. 